\title{
Forum
}

\section{The East London Classics Summer School}

\author{
Sarah Merali-Smith and Alicia Nongbri \\ The East London Classics Summer School, UK
}

We are two experienced teachers looking to make a small contribution to the Classics community.

We both met early in our careers, teaching Classics in the same secondary state school. We found that we had a lot in common; as well as our love for the subject, we were also first-generation ethnic minorities whose parents had immigrated to the UK in the 1960s, and whose choice to study Classics at A level and beyond had somewhat mystified our parents and families. Coming from Asian heritage, we felt that there were certain subjects, in particular the sciences, that dominated within our cultures, which consequently would have led to more conventional or expected career paths like medicine or dentistry. We decided not to follow this course of study, a decision which was definitely a deviation from the status quo in our communities. The reaction from our respective parents was disappointment and there was a difficulty in understanding what the subject was and to where it would lead in terms of career opportunities. Whilst we were growing up, there was limited Greek and Latin provision at our schools so we were fortunate to be presented with the rare opportunity to study Classical Civilisation at A level. The lure of Greek and Roman mythology, the literature, the civilisation, and the art of the ancient world was enticing from the outset. After gaining excellent qualifications in Latin and Greek at university, we went on ultimately to become respective Heads of Classics at different secondary schools. It was our own personal journeys and our shared interest in Classics which led both to our friendship (as well as a love of food and dancing!) and now to our partnership since we started the East London Classics Summer School.

The idea of the Summer School was to offer a London-based intensive revision language course for students preparing for their GCSE in Latin the following year. In light of Covid 19, and the significant periods of time pupils have spent learning from home, we felt there was an opportunity to provide them with a course not only to cover the more challenging aspects of the examination specification, but also to develop a broader understanding of the classical world that extends beyond the syllabus. One of our main priorities was to reach out to schools in the state sector where, as is often the case, students are taught Latin off-timetable, in lunch times or twilight sessions once a week or fortnight. The contact time can be adequate but sparse; students may not have had the I.T facilities to make sufficient progress whilst learning from home, or schools may have differed in remote teaching provision.

We secured a suitable venue, settled upon a fee to cover our costs, and put together a simple brochure and, in a matter of a few

Author of correspondence: @ELCSS2 eastlondoncss@gmail.com

Cite this article: Merali-Smith S and Nongbri A (2022). The East London Classics Summer School. Journal of Classics Teaching, 23, 73-74. https://doi.org/10.1017/S2058631021000714 weeks, managed to send it out to over 50 schools across London. Originally our intention was a small pilot group of around eight students, but we were quickly overwhelmed with responses by individuals, parents and schools alike. We ended up taking 17 students, all due to sit their Latin GCSE in the summer of 2022, and had to sadly turn some away since we had reached full capacity. The planning stage was intensive but fun. Both being experienced teachers, we knew exactly which pieces of Latin syntax we wanted to cover for the GCSE, and we simply split our list into two, and planned the lessons between us, then shared the material. Every session was planned meticulously, comprising notes, accompanying images which provoked questions about the classical world, sentences and unseen translation / comprehension passages for consolidation. We also ensured that our students left the course with revision materials from each session.

We wanted to be able to reach out to organisations, institutions and individuals whom we felt might be able to support us in our endeavour to make Classics more accessible to a wider range of students and enable them to study in a comfortable environment, where their Latin learning experience could be consolidated, improved and extended. We were thrilled when both Professor Mary Beard and Dr John Taylor offered financial contributions to be put towards the students' fees. Hugely encouraged by their support, we continue to feel motivated to seek funding for students who would struggle to meet the costs of the course. We were also lucky to have been able to secure the backing of some schools, who deemed the course valuable enough to want to pay for their students' attendance outright. This support has given us invaluable reassurance and determination and we plan to offer more bursaries next summer to our students.

The course ran in the first week of August 2021, in the meeting rooms of an architectural studio in central Homerton, Hackney, one of the most deprived boroughs of London. The students were divided into two smaller, seminar-style groups and all study materials and meals were provided. Each day saw four intensive language sessions, each roughly one hour, and focusing on a separate piece of core GCSE accidence/syntax. We had one teacher per group and the lessons were a mixture of teacher-fronted activities, pair and group tasks. The commitment and dedication of these students was exceptional; they were focused throughout, disciplined, enthusiastic and good-humoured. We were well and truly humbled by the end of the week, and held a Bacchanalian pizza feast on the last day as a congratulatory and celebratory treat!

We wanted to make sure that our students were presented with a super-curricular, non-linguistic setting to our lessons in order to enrich their appreciation of the world of Classics beyond the exam 
specification. We ended each day with a 'Golden Time' lecture, delivered by ourselves, where we explored a feature of the classical world. This summer, our lectures explored the Greek nude, Roman tombstones, mythology in Ovid's Metamorphoses, and the background to the Trojan War. Our hope was to inspire our students to further develop their studies and open themselves up to the multi-disciplinary avenues of the subject, showcasing aspects of archaeology, art history, literature, and philosophy. The study of Classics provides an opportunity for pause and reflection to consider the bigger issues of empire, of misogyny, of gender and race, and we wanted to be very explicit about how an understanding of these subjects can help to make big differences in today's world. We ended the week with a quiz and a final moment of contemplation on not just the value of Classics, but also its modern perception in society and the importance of the subject being accessible to all. The value of their voices in pushing beyond the boundaries of a subject that can be perceived as 'exclusive' was also a key topic of discussion.

Much to our delight, we received outstanding feedback from the students who attended the course and we have had much interest in providing other classics-related events; we have many plans in the pipeline! We will be holding a Latin Revision Day in April 2022 which will home in on the more complex Latin constructions, tricky vocabulary and GCSE translation skills, in readiness for examinations in May/June. Vocabulary drills will feature prominently on the agenda! We have set aside some spots for the students whom we had to turn away this summer, but there are still some spaces available. There has been discussion about the Summer School offering a Classics taster day or Classics fete for students in London state schools who have limited or no provision of the subject. Our own experience has illustrated that it can be challenging for pupils who are ethnic minorities to forge an obvious connection with the subject and that the Classics community may appear somewhat closed and intimidating, and so it was essential that our summer school events push against and challenge this perception. It has been pleasing that numerous organisations are now trying to recognise this, and we hope that we are playing some part.

We are hugely excited by the British Government's planned 'Latin Excellence Programme', where the subject will be taught in 40 state schools in disadvantaged areas of the country. Whilst we feel this will not rectify the reputation of Classics being an elitist subject, we think this is at least a step in the right direction in making Classics less exclusive, and we are excited about this much needed and long overdue change. We were inspired by Mary Beard's subsequent tweet where she heartily expressed a championing of the value of the programme and of Classics in general, in which she candidly iterated that our subject is not just for the 'posh white boys' 2 . This resonated with us and allowed us space to reflect on our own challenges upon entering the world of Classics.

We are in the very early stages of this project but what we are sure of is that we are advocates of diverse perspectives and simply want to champion the importance of every voice, and offer a welcoming space for expression and study of a subject that should be for all.

\section{Notes}

1 In July 2021 the Department for Education, announced a Latin for Excellence Programme for state-maintained schools in England. For details, see https:// www.gov.uk/government/news/thousands-more-students-to-learn-ancientand-modern-languages

2 See Beard in a video on the Department for Education Twitter feed, July 2021: https://twitter.com/educationgovuk/status/1421365123466383361 